\title{
REVERSE KNOWLEDGE TRANSFER FROM CENTRAL EUROPE TO WESTERN EUROPE: SELECTED CASE STUDIES
}

\author{
Sonia Ferencikova \\ School of Management, Bratislava, Slovakia \\ Jana Hrdlickova \\ School of Management, Bratislava, Slovakia
}

\begin{abstract}
Reverse knowledge transfer refers to the knowledge flow from the subsidiary to the parent company. This paper analyzes whether subsidiaries located in a former transitional country (Slovakia) transfer original knowledge to their parent companies in so-called developed Western Europe, and focuses on key drivers, communication channels, and contribution of such knowledge flow. Qualitative research with four multinational companies was conducted to identify reverse knowledge transfer cases and to analyze if the Slovak subsidiaries have the potential to contribute to the corporate knowledge and increase the performance of corporations in various functional areas.
\end{abstract}

Keywords: reverse knowledge transfer, corporation, subsidiary, performance, Slovakia

DOI: http://dx.doi.org/10.15549/jeecar.v7i1.340

\section{INTRODUCTION}

Reverse knowledge transfer from Central and Eastern Europe to Western Europe: does it really exist?

The international business research used to focus on traditional knowledge transfer from parent companies to their subsidiaries and from developed countries to developing countries. The situation has changed, and growing internalization and decentralization has initiated the studies about less frequent knowledge flows, including transfer from subsidiaries to the parent company and from less developed countries to the developed ones. According to Schotter and Bontis (2009),
"Reverse capability transfer is defined as a firm's replication of internal practices, which are performed in a superior way in some parts of the organization compared to other parts of the organization, and which are superior to internal and external alternative practices" (p.151).

Some research finds reverse knowledge transfer identical to the traditional one. Other opinions state that reverse transfer requires richer activities, more frequent personal interactions, parent facilitation, and a lot of guidance and effort (Borini et al. 2012). "The political complexities of reverse transfer can be more difficult to overcome than those of forward transfer" (Chung 2014, p. 229). 
Although the transfer mechanisms are similar, the reverse knowledge transfers were analyzed not so frequently as the classical ones, and the cases from transitional countries including Central Europe and Slovakia are completely missing.

To fill this gap, we study the companies operating in Slovakia to find reverse knowledge transfer cases. What determines this reverse knowledge transfer? We focus on the factors, drivers and motivations that support reverse knowledge transfer and on external corporate mechanisms supporting it. Reverse knowledge transfer should enhance competitiveness of multinational corporations and we study what is the contribution of the Slovak subsidiaries to it and to the corporate knowledge base.

There is no similar study about the reverse knowledge transfer cases from Central and Eastern Europe to Western Europe. Therefore, the ambition of the authors is to contribute to the international business literature on this topic by the case study research from this region, specifically from Slovakia.

\section{LITERATURE OVERVIEW}

The modern view of multinationals emphasizes the international network of the organizational units and their opportunities to recieve and contribute to the corporate knowledge base (Coakes 2006, Bezzera et al. 2013, Najafi-Tavani et al. 2014, Andersson et al. 2015). The subsidiaries' resources form a basis for knowledge exchange and allow each unit to benefit from the heterogenous competences available in the corporation.

The subsidiaries have different roles in the corporations: some are supposed to commercialize products and services, others conduct $R \& D$, and some manufacture products. The subsidiaries can either utilize the existing corporate knowledge and potentially adapt it if needed or generate new knowledge and create new skills (Mudambi et al. 2013). Development of new competences depends on the mandate that the parent company gives to the subsidiary. Based on the contribution of the subsidiaries to the corporate knowledge base, the following subsidiaries can be defined: local innovators, integrated subsidiaries, local implementators, global innovators (Ordoñez de Pablos 2006), or local implementators, specialized contributors, world leaders (Nair et al. 2015), or finally, subsidiaries adapting products to their context, subsidiaries developing global technological competences and contributing to existing knowledge and subsidiaries generating brand new practices (Rabbiosi 2011).

The research has identified many factors influencing knowledge transfer, some are supporting, and the others are hindering. Ling et al. (2009) formed a triad of the barriers related to knowledge transfer. He describes multiple individual obstacles, such as insufficient time for knowledge transfer, risk of job loss, lack of understanding of the importance of knowledge exchange, prevailing transfer of explicit knowledge, hierarchy barrier, lack of contacts, weak interpersonal contacts, poor communication, and interpersonal skills, age difference, gender difference, educational difference, weak networking, lack of trust, lack of recognition, doubts about knowledge quality, cultural difference. He also labels multiple organizational barriers, such as the unclear role of knowledge management, poor managerial skills, poor leadership, lack of motivational culture, insufficient infrastructure, lack of knowledge sharing tools, intra-company competition, limited communication, and knowledge flows. He also defines various technological barriers, for example, weak integration of knowledge and IT systems, outdated technologies, incompatible company systems, the gap between IT needs and employee skills, insufficient IT training.

The framework developed by Tseng (2015) about internal knowledge sharing consists of a sender, transfer, receiver, and knowledge factors. Sender factors relate to the organization, its knowledge base, willingness to share knowledge, and capacity to transfer knowledge. Receiver factors refer to learning capacity and motivation. Transfer factors include formal and informal transfer mechanisms. Knowledge factors are comprised of knowledge, complexity, and tacitness. As the sender starts the process of knowledge transfer, its motivation was identified as an essential factor.

Reverse knowledge transfer is fueled by the 
informal control from the parent company or by giving benefits for knowledge sharing. Trust, personal contacts between subsidiary managers, and headquarter managers advance reverse knowledge transfer. Mutual trust is especially helpful when exchanging abstract and tacit knowledge (Chung 2014).

The amount of knowledge owned by the subsidiary also affects reverse knowledge transfer. The increase of knowledge amount in the subsidiary means more attention from the parent company, and the intensity of reverse knowledge transfer will go up. When the subsidiary manages to further grow its knowledge base, the interest from the parent company will again strengthen, but it could happen that the subsidiary will realize its power in the corporation. Knowledge transfer will be equivalent to decreasing subsidiary power and control over its knowledge. However, in the context of long-term relations, we can also expect a cooperative approach - the subsidiary which passes on its own knowledge in the longer run is strengthening its role in the corporation (Mudambi et al. 2013).

The organizations can support knowledge transfer by the creation of conditions that are helpful for knowledge sharing: full ownership of the subsidiaries, atmosphere of trust, international human resource management, and frequent managerial contacts. Actors impacting transfer include culture, employee commitment and trust, and the use of incentives to encourage knowledge sharing, "knowledge-oriented culture, a technical and organizational infrastructure, senior management process orientation, clarity of vision and language, nontrivial aids, some level of knowledge structure and multiple channels of knowledge transfer" (Søndergaard et al. 2007:426). "The combination of factors has a stronger effect on reverse transfer than any one of them taken in isolation" (Chung 2014:245).

The multinational corporations that have global structures often organize managerial meetings, support employee mobility, and form virtual multinational project teams. The more frequent are the contacts of the managers from the headquarters and the subsidiaries, the more knowledge is transferred from the local entities (Chung 2014). Use of expatriates strengthens the relationship of the parent company and subsidiary. It ensures that the subsidiary follows the global practice (Tseng 2015), and at the same time, the expatriate indemnifies flow from the subsidiary. The employees who return from the international assignment are also a unique channel for knowledge transfer (Liu et al. 2014).

According to Minbaeva et al. (2014), not only skills but also motivation is affecting knowledge transfer. Knowledge transfer can be strengthened by the implementation of organizational motivators that support absorptive capacity. Further, human resource practices such as position definition, appraisal, employee rotation, decentralization, integration, and innovative culture can stimulate knowledge sharing. The more intense the systems of the international human resource management system, the more knowledge is transferred from the subsidiaries (Chung, 2014).

The company that compensates for knowledge sharing enhances the willingness of the managers to engage in knowledge exchange. However, Ling et al. (2009) recommend to use financial stimuli only ad hoc and rather integrate knowledge transfer into corporate value systems and job descriptions of each individual. Broad availability of ICT is also increasing knowledge exchange.

Both parties face the cost related to knowledge exchange, and partners expect to share it fairly. The subsidiaries of the multinational are willing to invest in a corporation and keep corporate membership; the committed subsidiary allocates resources into knowledge flows (Chen et al. 2011).

Based on the study of the relevant literature, our research questions are the following:

Question 1: Do the subsidiaries operating in Slovakia generate new knowledge that is transferred back to the parent companies?

Question 2: What determines the reverse knowledge transfer from the subsidiaries operating in Slovakia to their parents' companies?

Question 3: Is the reverse knowledge transfer from the subsidiaries operating in Slovakia supported by corporate mechanisms? 


\section{METHODOLOGY}

Our goal is to analyze the status of reverse knowledge transfer from the subsidiaries in Slovakia to their parent companies. Our intention is to define the types of transferred knowledge, the factors that influence the transfer of knowledge, together with the communication channels, and the potential of knowledge transfer.

We use primary and secondary data: secondary data is used mostly in the theoretical part to draw a picture of the (reverse) knowledge transfer status in literature, explain the background, antecedents, and importance, supporting tools and potential outcomes. All of this information comes from foreign studies; the cases and research pieces from Slovakia and Central Europe are not available. The information was found via the internet in academic databases.

For our study, the primary data is essential: we have chosen the case study research method in order to obtain the necessary information for answering the research questions. This design allows a lot of data and additional details to be collected and therefore offers information, which is normally a lot richer and in greater depth compared to other research methods (Yin, 2014). The depth of case study analysis should compensate for the limited representative sample of the interviewed firms, as it is typical for this sort of empirical research. The major technique that we use is the interview. Focused interviews, with the possibility to remain openended, are aimed to offer in-depth analysis and enhance the understanding of reverse knowledge transfer from Slovak subsidiaries.

Our case study sample was formed based on our information and judgment. Four companies confirmed their involvement in reverse knowledge transfer and their willingness to provide us with information. All respondents were asked to describe the case, the interviews were semi-structured with a standard template, and were conducted in 2018 and 2019. In each case, two in-depth interviews were conducted. The interviews took place in the subsidiary, lasted several hours, and were held in the local language (with the exception of ZUNO in English) with the senior managers involved in reverse knowledge transfer (managers from respective business function).

Semi-structured interviews allowed the researchers to explore the topic and build upon the respondent's answers. The interviews were conducted around the research questions. The responses were organized into themes on their content and were used to answer the research questions. Interviews were enriched by secondary data: company materials, and articles from the local press. On this base, we were able to describe the cases of reverse knowledge transfer, the drivers for knowledge creation, the process of its implementation, and the results.

\section{RESULTS}

Four investigated companies provided us with six reverse knowledge transfer cases, as listed in Table 1.

Table 1. Profile of the researched companies

\begin{tabular}{|l|l|l|l|l|}
\hline & JTI SR & Maresi SK & Tesco SK & ZUNO \\
\hline $\begin{array}{l}\text { Parent } \\
\text { company }\end{array}$ & $\begin{array}{l}\text { Japan Tobacco } \\
\text { International, } \\
\text { Inc. }\end{array}$ & $\begin{array}{l}\text { Maresi Austria } \\
\text { GmbH }\end{array}$ & Tesco Stores Limited & $\begin{array}{l}\text { Raiffeisen Bank } \\
\text { International } \\
\text { AG }\end{array}$ \\
\hline $\begin{array}{l}\text { Location of } \\
\text { the HQ }\end{array}$ & $\begin{array}{l}\text { Switzerland, } \\
\text { Geneva }\end{array}$ & Austria, Vienna & Czech Republic, Prague & Austria, Vienna \\
\hline Industry & $\begin{array}{l}\text { Fast-moving } \\
\text { consumer } \\
\text { goods - tobacco }\end{array}$ & $\begin{array}{l}\text { Fast-moving } \\
\text { consumer goods - } \\
\text { grocery }\end{array}$ & $\begin{array}{l}\text { Retail - grocery, non- } \\
\text { grocery products, service } \\
\text { related to retail sale }\end{array}$ & Banking \\
\hline $\begin{array}{l}\text { The size of } \\
\text { the Slovak } \\
\text { subsidiary }\end{array}$ & 35 employees & 10000 employees & 200 employees \\
\hline
\end{tabular}


The first case is JTI Slovak Republic (JTI SR). It was established in Slovakia in 2004 by Japan Tobacco International. JTI SR had limited resources, and the statistics and reports for it were prepared in excel tables or even by pen $\&$ paper by different retailers. Having multiple data systems and sources, JTI SR tried to integrate all of the information in one data warehouse and introduced QlikView, a business solution developed in cooperation with a local provider. QlikView is used as the key knowledge base for strategic commercial decisions as well as for monitoring and planning of sales and marketing initiatives (JTI 2018).

Knowledge sharing in JTI is facilitated by the headquarters so that each country can get benefit from innovative solutions. JTI SR passed its solution to Georgia and Denmark. Sharing QlikView system with the headquarters strengthened the position of JTI SR within the company (JTI 2018).

The second case is Maresi SK. It is food broker company, that sells primarily the brands of the other companies. It used to distribute Ferrero, Storck, Chipita and Haribo, and suffered losses after these brands terminated their cooperation with Maresi. Thus, Maresi lost significant revenue and needed to react. The managers focused on cost reduction, firstly introduced multiple optimization measures (stopped the unit sale, set up minimal order value of $200 €$, split the Slovak region into 6 areas and optimized the logistic routes, set up logistic cycles to achieve better efficiency, applied EDI that allowed to issue invoices faster and translated to improved cash flow) which resulted in the declined logistic cost. Maresi eliminated own transport and warehouse and found an external logistic partner who was able to achieve synergies and other savings due to the use of specialized systems, expertise and economies of scale (Slobodová 2018).

The cost reduction in logistics function led the headquarters to do an audit of logistics in all other countries. The whole process of cost analysis, scenario models, assessment, partners' identification and negotiation was the subject of reverse knowledge transfer. All Maresi subsidiaries gradually outsourced the logistic and often introduced some further optimizations developed in Slovakia. Maresi SK shared knowledge using personal communication channels. The corporation is supportive of knowledge exchange, and employees have several opportunities to communicate (Slobodová 2018).

The third case is the Tesco subsidiary. The marketing function in Tesco for the CE region is centered in Prague. Although the communication materials (POS materials) used in the stores were harmonized within the region, the Slovak marketing team felt the need to strengthen the "low price message." They checked the possibilities of the stores to imprint the pricing in the outlets and adjusted the designs accordingly. The local team also changed the customer satisfaction survey that was traditionally organized as face to face interviews: online customer satisfaction research proved to be more efficient. Moreover, the team thought also of how to persuade customers to take part in the online study they developed a program of robust communication and customer motivation. Tesco SK also found a way to cooperate with dozens of local producers. Often criticized for preferring global players, the commercial department put together a plan for how to manage small deliveries, regionally differentiated, with unstable volume and price (Almasyova 2018).

The three marketing \& commercial projects delivered positive results: advertising materials with a positive impact on the customers, the savings on customer satisfaction research, widen the range of local products that were well received by the customers, authorities, and local producers. The success of the initiatives caused Tesco in other countries to introduce the same projects. The detailed information about the projects and their outcomes were presented to the headquarters, and communication was done via e-mails, phone, videoconferences, and also personal meetings.

The fourth case is ZUNO, the daughter company of Raiffeisen Bank International (RBI) active in Central and Eastern Europe. ZUNOBank is a modern digital bank that was active in Slovakia from December 2010 till June 2017. ZUNO subsidiary in Slovakia was the first standalone online bank of RBI, and the Slovak market was selected due to its distance proximity to Vienna and its favorable labor cost. 
ZUNO was established as a greenfield investment, fully owned by RBI, and its strategic objective was to deploy direct banking via online service, targeting the clients who wanted to communicate with the bank via the internet.

Knowledge related to the establishment of the branch office in Slovakia was very useful when setting up the same business in the Czechia in 2011. This knowledge was also used when preparing ZUNO operations in Hungary and Poland. The most beneficial was digital technological know-how, previously absent at this level of detail in RBI. Additional knowledge was transferred to RBI headquarters from ZUNO Slovakia, i.e., experience in digital banking, online customer relationship management, and providing banking services solely via the internet. This expertise, together with a few experienced former ZUNO employees were transferred back to RBI and is of high value in supporting RBI's ongoing digital banking agenda also after the discontinuation of ZUNO (Arzner 2018).

\section{DISCUSSION}

We conclude that Slovak subsidiaries are able to generate new knowledge. (Question 1). In line with the relevant literature, we see that new knowledge is generated when the organization lacks adequate practices - the creation of new knowledge is driven either by subsidiary ambition to grow or by its need to solve a specific problem. Our examples come from various business functions - it is obvious that Slovak subsidiaries generate new knowledge in many different business areas.

Literature suggests that the most important factor effecting reverse knowledge transfer is the entry mode. Having analyzed the reverse knowledge transfer cases, we recognize the integration as the key aspect for knowledge sharing. Well-integrated subsidiaries like Tesco shared knowledge smoothly, irrespective of market entry mode.

Based on our research the most relevant factors for reverse knowledge transfer from Slovak subsidiaries are: corporate structure, control mechanisms and subsidiaries' role. (Question 2). These important prerequisites vary and are defined by the parent company, as a result of strategy, vision and values. Tesco's structure is set up as international which is encouraging knowledge transfer, ZUNO was given a mandate of innovator and generated complex know-how, the intensity of the control mechanisms varied from very strict in JTI to very weak in ZUNO and are reflected in daily knowledge-sharing routines. Values of cooperation, communication, and way of working translate to opportunities that the subsidiaries have to exchange knowledge.

We learned how important it is that the parent companies initiate regular opportunities for subsidiaries to exchange experience: international meetings, workshops, conferences, etc., provide with modern ICT so that knowledge can flow among corporate units. (Question 3). Although each knowledge was documented in respective codified form, it also contained a tacit component that triggered personal communication.

Knowledge transfer cost appears minor. The cost includes time spent on communication, travel expense, and ICT use. Similarly, the cost of implementation in new countries seems to be affordable. We did not see any substantial cost related to knowledge transfer that could stop the process.

Quantifying the impact of new knowledge is very challenging. In the case of Maresi's logistics outsourcing, the effect is the decrease of logistic cost ratio on revenues; however, this ratio is just indicative as it depends on the turnover. The effects of new knowledge can be rather detected indirectly through qualitative statements. We are able to define the areas in which performance improved or in which issues were solved. Deployment of commercial data in JTI supports the sales and marketing function and thus company competitiveness; outsourcing of logistics in Maresi reduced cost, enhanced POS designs, and enlarged product offer; and online system of the research improved Tesco's competitiveness and save costs. ZUNO generated digital technologies important for RBI competitiveness. Reverse knowledge transfer conveys benefits from the originator to the parent company and also to other subsidiaries. Moreover, local subsidiaries can gain additional acknowledgment of the parent company; JTI gained a strong reputation 
as a competent subsidiary that was advantageous when requesting some further investment projects, and the Maresi manager was appointed to lead the project team auditing the logistic function in the corporation. The complex characteristics of reverse knowledge transfer cases are in Table 2.

As previously stated, the role of expatriates in reverse knowledge transfer is generally undeniable: they can inspire and motivate reverse knowledge transfer: the best cases are the Centre of Excellence Centers in Central and Eastern Europe. However, there were expatriates present only in one case studied (ZUNO); all the other three companies studied did not have any expatriate in the management, i.e., they did not have any share on the creation of the knowledge in the subsidiaries.

One question in our interviews was centered at the participation of local HR in motivation and support of the reverse knowledge transfer: we learned that the role of the local HR has not been significant because it is not considered to be a "strategic partner" (what is in line with the other research in Central and Eastern Europe, see Poor et al., 2019)

Our paper does not fully cover the topic of reverse knowledge transfer. We uncover the attributes that can be further studied more in depth; also, the sample can be enlarged including other sectors/industries. A challenging task is also to develop methodology to measure the benefits of reverse knowledge transfer for the corporations.

Reverse knowledge transfer offers space for additional research: new objectives require quantitative methodology that would allow generalization of the findings. Combined synthesis with our research can form a complex framework and understanding of the phenomena within Slovak environment.

\section{CONCLUSION}

This paper is the first one studying the reverse knowledge transfer from Slovakia. We learned that the local subsidiaries are important creators of new practices. We showed that the multinational corporation can increase its competitive advantage via effective management of reverse knowledge transfer, by combining local knowledge, technological and managerial know-how, and its sharing within its own boundaries. We learned that the subsidiaries have huge potential to generate new practices, innovate products, improve ways of working, and pass it to the parent companies. We have verified the idea that new knowledge is being created in the absence of a global solution. We also support the finding that even a common subsidiary without the role of the research centre can generate unique initiatives that help achieve better results. Knowledge sharing is a very effective tool to gain new solutions - utilization of knowledge from the other subsidiaries is nowadays common practice that further supports efficiency and synergies. In some cases, the solutions are being developed as global within international projects.

To achieve a smooth knowledge exchange, the parent companies do take part in the process, usually as facilitators. Therefore, the parent companies need to have an overview of the local activities and their weaknesses. The parent companies are also supposed to create a global culture that supports communication and cooperation, which is often achieved via control mechanisms, formal and informal opportunities to share experiences, international human resource management, or even matrix organization.

Looking at the results, we found reverse knowledge transfer as very beneficial: although it is difficult to quantify the effect of knowledge sharing, we saw the benefits of increased competitiveness, effectiveness, and cost reduction. The inflow of knowledge avoids duplicate development cost, and reverse transfer further helps coordinate a global strategy, align the product offer, drive technological development, monitor the development of the subsidiaries, align knowledge processes, and mitigate the risk, thanks to earlier implementation elsewhere. Finally, a subsidiary that is sharing its knowhow increases its reputation in the corporation.

As there were not any publications describing specific knowledge transfer cases from Slovakia, we believe we have contributed to that literature. We confirm the active role of subsidiaries operating in Slovakia in knowledge 
creation and sharing. This finding is especially relevant for foreign investors who plan to enter the Slovak market. In the case of investing in Slovakia, they will find not only the new market or advantageous location for their facilities but also a very promising knowledge source that can further support performance on the corporate level.

\section{REFERENCES}

Ahlstrom, D. (2017) How to publish in academic journals: Writing a strong and organized introduction section, Journal of Eastern European and Central Asian Research, 4,2, 9 p.

Ahlstrom, D., Bruton, G.D., and Zhao, L. (2013) Turning good research into good publications, in Nankai Business Review International, 4,2, 92-106

Almasyova, S. (2018): Reverse knowledge transfer in Tesco. Tesco. 1. June 2018. Personal communication.

Andersson, U. et al. (2015): Unpacking interunit knowledge transfer in multinational enterprises, in: Global Strategy Journal [online database], 5, 3, 241-255. [cit. 201901-10].

Argot, L., and Ingram, P. (2000): Knowledge Transfer: A Basis for Competitive Advantage in Firms, in: Organizational Behavior and Human Decision Processes [online database], 82, 1, 150-169. [cit. 2018-11-14].

Arzner, S. (2018): Reverse knowledge transfer case in Raiffeisen Bank International. Raiffeisen Bank International. 17. November 2018. Personal communication.

Bezzera, M. A., Costa, S., and Borini, F. M. (2013): Reverse Knowledge Transfer: A Comparison Between Subsidiaries of Emerging Markets and Subsidiaries of Developed Markets, in: Revista Ibero-Americana de Estratégia [online database], 12, 4, 67-90. [cit. 201901-01].

Borini, F. et al. (2012): The reverse transfer of innovation of foreign subsidiaries of Brazilian multinationals, in: European Management Journal [online database], 30, 3, 219-231. [cit. 2017-10-01].

Easterby-Smith, M., Lyles, M. A., and Tsang, E. V. K. (2008): Inter-Organizational Knowledge
Transfer: Current Themes and Future Prospects, in: Journal of Management Studies [online database], 45, 4, 677-690. [cit. 2015-11-14].

Chung, L. (2014): Headquarters' Managerial Intentionality and Reverse Transfer of Practices, in: Management International Review [online database], 54, 2, 225-252. [cit. 2017-06-01].

JTI. (2018): Knowledge multitransfer in JTI. Internal material.

Ling, Ch. W., Sandhu, M. S., and Jain, K. K. (2009): Knowledge sharing in an American multinational company based in Malaysia, in: Journal of Workplace Learning [online database], 21, 2, 125-142. Retrieved from: ProQuest Research Library [cit. 2018-06-01].

Liu, X., Jiangyong, L., and Choi, S.-J. (2014): Bridging Knowledge Gaps: Returnees and Reverse Knowledge Spillovers from Chinese Local Firms to Foreign Firms, in: Management International Review [online database], 54, 2, 253-276. [cit. 2017-10-01].

McKeenN, J. D., Zack, M. H., and Singh, S. (2006): Knowledge Management and Organizational Performance: An Exploratory Survey: presentation [online] Hawaii: International Conference, 2006. [cit. 2016-01-06].

Minabeva, D. B., Pedersen, T., Bjorkman, I., and Fey, C. F. (2014): A retrospective on: MNC knowledge transfer, subsidiary absorptive capacity, and HRM, in: Journal of International Business Studies [online database], vol. 45, p. 52-62. [cit. 2018-0501].

Mudambi, R., Piscitello, L., and Rabbiosi, L. (2014): Reverse Knowledge Transfer in MNEs : Subsidiary Innovativeness and Entry Modes, in: Long Range Planning [online database], 47, 1-2, 49-63. Retrieved from: ProQuest Research Library [cit. 2016-10-06].

Najafi-Tavani, Z., Zaefarina, G., Naudé, P., and Giroud, A. (2015): Reverse Knowledge Transfer and Subsidiary Power, in: Industrial Marketing Management [online database], vol. 48, p. 103-110. Retrieved from: ProQuest Research Library [cit. 2018-01-01].

Najafi-Tavani, Z., Giroud, A., and Andersson, U. (2014): The interplay of networking activities and international knowledge 
actions for subsidiaries influence within MNCs, in: Journal of World Business [online database], 49, 1, 122-131. [cit. 2018-10-01].

Najafi-Tavani, Z., Giroud, A., and Sinkovics, R. R. (2011): Mediating Effects in Reverse Knowledge Transfer Processes: The Case of Knowledge-Intensive Services in the U.K, in: Management International Review [online database], 52, 3, 461-488. [cit. 2017-10-06].

Nair, S. R., Demirbag, M., and Mellahi, K. (2015): Reverse Knowledge Transfer from Overseas Acquisitions: A Survey of Indian MNEs, in: Management International Review [online database], 55, 2, 277-301. [cit. 2017-01-10].

Nooshinfard, F., and Nemati-Anaraki, L. (2014): Success factors of inter-organizational knowledge sharing: a proposed framework, in: The Electronic Library [online database], 32, 2, 239-261. Retrieved from: ProQuest Research Library [cit. 2018-01-06].

Orodonez de Pablos, P. (2006): Transnational corporations and strategic challenges: An analysis of knowledge flows and competitive advantage, in: The Learning Organization [online database], 13, 6, 544559. [cit. 2017-07-01].

Ping-Ju Wu, S., Straub, D. W., and Liang, T.-P. (2015). How Information Technology Governance Mechanisms and Strategic Alignment Influece Organizational Perfomarnace: Insights from a Matched Survey of Business and IT Managers, in: MIS Quarterly [online database], 39, 2, 497-518. [cit. 2017-03-01].

Poor, J. et al. (2019) Global, regional and local similarities and differences in HRM in light of Cranet researches (2008-2016) in: Journal of Eastern European and Central Asian Research [online database], (JEECAR), 6,1 [cit. 2020-01-14].

Rabiossi, L. (2011): Subsidiary Roles and Reverse Knowledge Transfer: An Investigation of the Effect of Coordination Mechanism, in: Journal of International Management [online database], 17, 2, 97-113. Retrieved from: scholar.google.com [cit. 2018-10-01].

Schotter, A. and Bontis, N. (2009): Intraorganizational knowledge exhange : An examination of reverse capability transfer in multinational corporations, in: Journal of
Intellectual Capital [online database], 10, 1, 149-164. [cit. 2018-10-01].

Sondergaard, S., Kerr, M., and Clegg, C. (2007): Sharing knowledge: contextualising sociotechnical thinking and practice, in: The Learning Organization [online database], 14, 5, 423-435. [cit. 2019-12-29].

Slobodová, R. (2018): Reverse knowledge transfer case in Maresi. Maresi. 1. July 2017. Personal communication.

Tseng, C.-H. (2015): Determinants of MNCE's Knowledge Inflows to Subsidiaries: A Perspective on Internalization Advantages, in: Management International Review [online database]. vol. 55, p. 119-150. [cit. 2018-05-01]

Yin, R.K. (2014) Case study research design and methods ( $5^{\text {th }}$ ed.) Sage. 282 p. 
Table 2. Attributes of reverse knowledge transfer cases in the studied companies

\begin{tabular}{|c|c|c|c|c|}
\hline & JTI & Maresi & Tesco & ZUNO \\
\hline $\begin{array}{l}\text { Subsidiaries' } \\
\text { management }\end{array}$ & Centralization & Centralization & $\begin{array}{l}\text { Distributed accountabilities and } \\
\text { responsibilities }\end{array}$ & Decentralization \\
\hline $\begin{array}{l}\text { Functional area relevant } \\
\text { to the case }\end{array}$ & IT & Logistics & Sales and marketing & Digital banking \\
\hline Knowledge type & Explicit & Tacit & Tacit & Tacit \\
\hline $\begin{array}{l}\text { Knowledge receiving in } \\
\text { the respective area }\end{array}$ & $\begin{array}{l}\text { Received partial IT } \\
\text { systems }\end{array}$ & Nothing received & $\begin{array}{l}\text { Other marketing and sales } \\
\text { initiatives received }\end{array}$ & Nothing received \\
\hline $\begin{array}{l}\text { Driver for knowledge } \\
\text { generation }\end{array}$ & $\begin{array}{l}\text { Ambition to enhance } \\
\text { the existing IT systems }\end{array}$ & Cost reduction need & $\begin{array}{l}\text { Ambition to enhance } \\
\text { communication towards } \\
\text { customers, researching, intensify } \\
\text { cooperation with local } \\
\text { producers }\end{array}$ & $\begin{array}{l}\text { Role of innovator - } \\
\text { mandate to establish } \\
\text { digital bank }\end{array}$ \\
\hline Knowledge subject & Data processing system & $\begin{array}{l}\text { Optimization, logistics } \\
\text { outsourcing }\end{array}$ & $\begin{array}{l}\text { Advertising materials, Online } \\
\text { customer satisfaction study, } \\
\text { Project of cooperation with } \\
\text { small producers }\end{array}$ & $\begin{array}{l}\text { Online banking, mobile } \\
\text { banking }\end{array}$ \\
\hline $\begin{array}{l}\text { Benefits of new } \\
\text { knowledge }\end{array}$ & $\begin{array}{l}\text { More qualified and } \\
\text { faster planning and } \\
\text { decisions }\end{array}$ & Cost reduction & $\begin{array}{l}\text { Customer orientation, trade } \\
\text { partnership with small local } \\
\text { producers }\end{array}$ & $\begin{array}{l}\text { Servicing modern } \\
\text { digital-oriented clients }\end{array}$ \\
\hline Impact of new knowledge & Competitiveness & Savings & Competitiveness, savings, image & Competitiveness \\
\hline $\begin{array}{l}\text { Reverse knowledge } \\
\text { transfer tool }\end{array}$ & $\begin{array}{l}\text { Personal } \\
\text { communication }\end{array}$ & Personal communication & $\begin{array}{l}\text { Direct communication - } \\
\text { videoconference }\end{array}$ & $\begin{array}{l}\text { Personal } \\
\text { communication }\end{array}$ \\
\hline $\begin{array}{l}\text { Benefits of sharing } \\
\text { knowledge }\end{array}$ & Strengthening position & $\begin{array}{l}\text { Appointment to lead a } \\
\text { similar project on an } \\
\text { international level }\end{array}$ & $\begin{array}{l}\text { Knowledge exchange is common } \\
\text { practice - no extra benefits }\end{array}$ & NA \\
\hline $\begin{array}{l}\text { Countries that } \\
\text { implemented knowledge } \\
\text { from Slovak subsidiary }\end{array}$ & Denmark, Georgia & $\begin{array}{l}\text { Austria, Hungary, Czech } \\
\text { Republic }\end{array}$ & $\begin{array}{l}\text { Czech Republic, Hungary, } \\
\text { Poland, Greece }\end{array}$ & Czech Republic \\
\hline
\end{tabular}




\section{ABOUT THE AUTHORS}

Sonia Ferencikova, email: sferencikova@vsm.sk

Dr. Sonia Ferencikova is the Professor at the Department of Management at School of Management in Bratislava, Slovakia, and holds degrees in international business from the Economic University, Bratislava. She teaches international management at home institution; in addition, she has lectured as Visiting Professor in top universities in the USA, Australia, France, Austria, Germany, Switzerland, Belgium, Finland, Czech Republic, Hungary, and Ukraine. Her research is focused on market entry strategies, investing, and doing business in Central and Eastern Europe. Her numerous publications on these subjects include more than sixty journal articles, case studies, and research papers published in Europe and the USA as well as ten books and more than twenty co-authored books.

Dr. Jana Hrdlickova is Trade Marketing Manager in Mattoni. Except for a doctoral degree from School of Management, Bratislava, she holds the degrees in marketing from Economic University, Bratislava, and in sales from Sales Academy Bratislava. 